\title{
Filosofia e Webcomics: Uma análise neopragmatista de Zen Pencils $^{1}$ \\ Philosophy and Webcomics: A neopragmatist analysis of Zen Pencils
}

10.11606/2316-9877.2021.v9i2.174089

\author{
Heraldo Aparecido Silva ${ }^{2}$ \\ Universidade Federal do Piauí (UFPI) \\ John (Jéssica) Agne Campelo Nunes ${ }^{3}$ \\ Universidade Federal do Piauí (UFPI)
}

\section{Resumo}

Tem como objetivo analisar as webcomics Zen Pencils a partir das contribuições teóricas do filósofo neopragmatista Richard Rorty sobre os gêneros narrativos. O aporte teórico baseia-se nos escritos de Moya (1993), Rorty (2006; 2007), McLaughlin (2005), McCloud (2008), Eisner (2010), Than (2012), dentre outros. Visa contribuir para o fomento de estudos e pesquisas sobre webcomics no âmbito filosófico e educacional dentro dos parâmetros do neopragmatismo.

Palavras-Chave: História em quadrinhos. Webcomics. Filosofia. Neopragmatismo.

\begin{abstract}
It aims to analyze Zen Pencils webcomics, based on the theoretical contributions of neopragmatist philosopher Richard Rorty on narrative genres. The theoretical contribution is based on the writings by Moya (1993), Rorty (2006; 2007), McLaughlin (2005), McCloud (2008), Eisner (2010), Than (2012), among others. It aims to contribute to the promotion of the study and the research on webcomics in the philosophical and educational scope within the parameters of neopragmatism.
\end{abstract}

Keywords: Comics. Webcomics. Philosophy. Neopragmatism.

\footnotetext{
${ }^{1} \mathrm{O}$ artigo é parte do resultado final de uma pesquisa de Iniciação Científica - CNPQ, desenvolvida durante o biênio 2019-2020 na UFPI, que tem como título Neopragmatismo e Webcomics: análise de Zen Pencils, na área de Filosofia da Educação, e orientada pelo prof. Dr. Heraldo Aparecido Silva.

${ }^{2}$ Doutor em Filosofia pela Universidade Federal de São Carlos - UFSCAR. Professor Associado na Universidade Federal do Piauí - UFPI. Professor Permanente do Programa de Pós-Graduação em Filosofia - PPGFIL/UFPI. E-mail: heraldokf@yahoo.com.br. (D) https://orcid.org/0000-00015533-0726.

${ }^{3}$ Especialista em Docência do Ensino Superior pela Universidade Estadual do Piauí - UESPI. Licenciado em Letras/Inglês pela Universidade Estadual do Piauí - UESPI. Graduando em Artes Visuais pela Universidade Federal do Piauí - UFPI. Bolsista de Iniciação Científica - PIBIC/UFPI (2019-2020). E-mail: johnagninunes@gmail.com. (D) https://orcid.org/0000-0003-1034-4007.
} 


\section{Introdução}

Desde os primórdios da humanidade, a Arte vem ocupando um espaço bastante importante na formação do caráter humano. Com ela, a comunicação se manifestou de um modo criativo, e, assim, o homem pode se expressar por meio dela, às vezes de uma forma que nem as palavras explicariam.

A história em quadrinhos é uma das formas de comunicação que usa a arte para mostrar aos leitores seus objetivos e temas, muitas vezes direta e indiretamente. Elas podem ser utilizadas na educação, na política, na diversão, na filosofia. É na questão filosófica que trataremos este trabalho com base no neopragmatismo de Richard Rorty e o objeto a ser estudado será as webcomics Zen Pencils.

\section{1 - Histórias em quadrinhos e webcomics}

Mas, afinal de contas, o que é a história em quadrinhos? De acordo com Pessoa (2014), como o próprio nome diz, é uma história contada em quadros (também chamado vinhetas) através de imagens, com ou sem linguagem escrita. Ela tem o objetivo de narrar histórias dos mais variados gêneros e estilos.

Eisner (2013, p.15) aponta que "a forma da história é um veículo para transmitir informação numa maneira de fácil absorção." Ou seja, ela transmite suas informações de maneira clara para o receptor em forma de linguagem visual e, algumas vezes, escrita. As histórias em quadrinhos são geralmente publicadas no formato de revistas, livros ou em tiras publicadas em jornais e revistas. Atualmente, elas têm sido utilizadas na internet também.

O homem vem se utilizando de desenhos e outros elementos gráficos desde a pré-história, deixando sua marca nas paredes das cavernas com as pinturas rupestres. Como lannone e lannone (1996) explicam, eles retratavam o misticismo, o cotidiano e suas aventuras com esses elementos. Porém, as precursoras das histórias em quadrinhos surgiram apenas no século XIX e elas não apresentavam ainda a forma atual; no entanto, elas eram muito parecidas. Os desenhos predominavam e os textos não eram muito comuns, às vezes não apareciam na história. A escrita, no geral, vinha em forma de prosa ou verso, e o diálogo era quase inexistente. 
nascimento da história em quadrinhos aconteceu em meados do século XIX, quase simultaneamente na Europa e nos Estados Unidos. Os destaques entre os autores de histórias contadas por meio de imagens eram os europeus Rudolphe Töpffer (1799-1846), Georges Colomb (1856-1945) e Wilhelm Busch (1832-1908). Töpffer, suíço, criou personagens como Cryptogame, Jabot e M. Vieux-Bois e suas histórias receberam elogios de grandes artistas como Johann Wolfgang von Goethe, autor de Fausto e Os sofrimentos do jovem Werther (MOYA, 1993).

Georges Colomb foi apontado por muitos como o criador da primeira da história em quadrinhos moderna. Ele foi responsável pela criação da Família Fenouillard, sob o pseudônimo de Christophe, em 1889. Ele nunca utilizou balõezinhos, mas adicionava textos sob seus quadros. Moya (1993, p. 12) afirma que Colomb "[...] estava avançado para seu tempo e é considerado um dos que mais contribuíram para os comics no seu nascedouro".

O alemão Busch é reconhecido como o inspirador das histórias em quadrinhos norte-americanas, e sua temática difere da de Töpffer. Enquanto as historietas de Töpffer eram basicamente figurativas, raramente algumas cenas apresentavam textos e eram de fantasia, Busch mostrava em suas histórias um humor pesado e satírico. Busch dedicou-se à caricatura após a Revolução Alemã de 1848 (MOYA, 1993).

Com o passar dos anos, seções humorísticas surgiram nos jornais, trazendo histórias em quadrinhos em seu conteúdo. Uma delas foi o suplemento dominical do New York World, que publicou a série Hogan's Alley, desenhada por Richard Felton Outcault. Outcault ficou famoso por ter introduzido o diálogo junto aos personagens e não no rodapé (MOYA, 1993). Ele criou personagens como The Yellow Kid (O Garoto Amarelo) que foi muito importante para o início da história em quadrinhos atual. Com o sucesso de The Yellow Kid, várias histórias passaram a ser criadas e publicadas. Foi com Outcault que o termo "jornalismo amarelo", ou seja, jornalismo sensacionalista, surgiu. De acordo com Moya (1993), o termo surgiu por conta do camisolão do menino pobre dos guetos de Nova York.

A história em quadrinhos, a partir deste ponto, passou por uma série de mudanças, evoluindo e criando estilos dentro do conceito. Além das tiras diárias, surgiram os gêneros de aventuras e super-heróis (como o Superman de Jerry 
Siegel e Joe Shuster em 1938) e renovações a partir de 1949 com o personagem Pogo de Walt Kelly. Destaques vieram com Charlie Brown, Lucy e Snoopy (Xereta) da série Peanuts, de Charles Schulz, O Recruta Zero e Pimentinha, Modesty Blaise, Valentina, Tex, Barbarella, Asterix e Mafalda. Outros destaques focaram em temas de ficção e fantasia como os quadrinhos de Moebius, pseudônimo de Jean Giraud, e Spirit, de Will Eisner. Hoje em dia, Will Eisner dá seu nome ao prêmio das histórias em quadrinhos, considerado o "Oscar" das HQs, o prêmio Will Eisner, cerimônia iniciada em 1988.

No Brasil, a data oficial da primeira ilustração foi estabelecida como 14 de dezembro de 1837, A Campainha e o Cujo de Manuel Araújo de Porto-Alegre (1806-1879). Angelo Agostini (1843-1906) que ilustrou revistas locais e criou sua própria publicação. Sua primeira história com personagem fixo apareceu na Vida Fluminense em 30 de janeiro de 1869, As Aventuras de Nhô Quim ou Impressões de uma Viagem à Corte. Ele também criou As Aventuras de Zé Caipora. O Jornal da Infância pode ser considerado como a possível precursora das revistas infantis, lançada em 2 de fevereiro de 1898. O Tico Tico, em 1905, iniciou o marco das publicações dedicadas às crianças no Brasil. Ela apresentou personagens de artistas brasileiros famosos como Lamparina, de J. Carlos; Joca Bemol, Barão de Rapapé e Chico Muque, de Max Yantok e as Zé Macaco e Faustina, de Alfredo Storni (MOYA, 1993).

As histórias em quadrinhos brasileiras foram publicadas em suplementos como A Gazetinha, do jornal A Gazeta, e o Suplemento Juvenil, do jornal $A$ Nação, criado por Adolfo Aizen. Aizen é considerado como o principal incentivador dos quadrinhos no Brasil. Ele lançou o Mirim em 1938, fundou a Editora Brasil-América (EBAL) e publicou sua primeira revista O Herói, em 1947. Roberto Marinho, em 1939, lançou O Globo Juvenil em 1937 e Gibi em 1939, que foram muito populares na época, rivais do Suplemento Juvenil.

Outras histórias em quadrinhos foram criadas durante o restante do século XX, cada uma com um objetivo de propagar a forma de comunicação entre leitores e artistas.

Com o advento do ciberespaço e da telefonia móvel, os quadrinhos começaram a se adaptar para este tipo de tecnologia. De acordo com Santos, Corrêa e Tomé (2013, p. 41-42), 
A internet tornou-se um fator importante para a divulgação de quadrinistas novos, principalmente para aqueles cujos trabalhos não se encaixam nos parâmetros estéticos e temáticos das editoras comerciais. [...] Criar um e-zine ou um site pessoal para disponibilizar textos e histórias em quadrinhos - até como uma forma de portfólio eletrônico - pode ser um modo mais simples, barato e rápido de expor opiniões e narrativas sequenciais do que fazer uma publicação impressa.

Foi desta forma que as webcomics ganharam espaço no mundo da era digital, ajudando o artista a se promover facilmente por meio de mídias sociais como o Twitter, Instagram, Facebook, dentre outros. Utilizando do próprio perfil de várias mídias na internet, estes ainda contam com sites de seu domínio (McCLOUD, 2008).

Foi a partir da década de 1980 que os artistas começaram a se aventurar nos recursos da computação gráfica nas histórias em quadrinhos (SANTOS, CORRÊA e TOMÉ, 2013). A Marvel e a DC, as duas principais editoras de quadrinhos dos Estados Unidos, resolveram investir em duas graphic novels com este tipo de tecnologia: O Homem de Ferro - Crash, de Mike Saenz (roteiro e arte) e Batman - Digital Justice, de Pepe Moreno, publicadas pela Editora Abril no Brasil. Os fanzines também adotaram métodos da computação gráfica em suas histórias.

Com o tempo, o computador passou a ser mais que um instrumento de auxílio na criação de histórias em quadrinhos. Ele também se tornou um dos veículos mais utilizados pelos artistas para a publicação e divulgação de seus quadrinhos de acordo com (MAGALHÃES, 2005).

\section{2 - Filosofia nas histórias em quadrinhos}

Um ponto em comum com ambas as partes, quadrinhos e filosofia, encontra-se claramente no livro Comics as philosophy (Histórias em quadrinhos como filosofia) de Jeff McLaughlin:

Quando lemos quadrinhos, fazemos uma série de escolhas estéticas e filosóficas. Embora essas escolhas sejam geralmente feitas inconscientemente, elas são, no entanto, decisões reais que enfrentamos toda vez que abrimos a seção de tirinhas do jornal ou abrimos uma nova história em quadrinhos. Desde o início, então, a forma dos quadrinhos - sua linguagem e como a entendemos - é repleta de dilemas filosóficos. Quando começamos a analisar o conteúdo dos 
quadrinhos, podemos enfrentar suas preocupações teóricas por meio de várias histórias, arcos narrativos, estilos de desenho e comentários (McLAUGHLIN, 2005, p. 11, tradução nossa ${ }^{4}$ ).

É interessante ressaltar que Rorty (2007) explica que o romance, o cinema, o programa de televisão, de forma lenta, mas sistemática, estão substituindo o sermão e o tratado para transmitir a mensagem de mudança e progresso morais. Por mais que ele não tenha diretamente citado as histórias em quadrinhos, ele está se referindo às mídias da cultura pop no geral. $\mathrm{O}$ autor também aborda a importância da linguagem para a formação do ser humano moral:

[...] substituir a demonstração pela dialética, como método da filosofia, ou descartar a teoria da verdade calcada na correspondência, não constitui uma descoberta sobre a natureza de uma entidade preexistente, chamada "filosofia" ou "verdade". Equivale a mudar nossa maneira de falar e, com isso, a mudar o que queremos fazer e o que pensamos ser (RORTY, 2007, p. 51-52).

Os quadrinhos abordam várias questões éticas e morais, mesmo que sejam de maneira indireta. Nas obras Comics as philosophy e Los superhéroes y la filosofia (MORRIS, MORRIS, 2010), vários autores destacam quadrinhos que elaboram conteúdos éticos e morais, analisando-os do ponto de vista de certos filósofos e seus estudos. O neopragmatismo de Rorty (1999) defende a literatura como caráter inspirador para a filosofia, já que tipicamente ela não é produzida por operações de métodos, uma ciência, uma disciplina ou uma profissão:

Você não pode, por exemplo, encontrar valor inspirador em um texto ao mesmo tempo em que o vê como o produto de um mecanismo de produção cultural. Ver um trabalho dessa maneira dá entendimento, mas não esperança, conhecimento, mas não autotransformação. Pois conhecimento é uma questão de colocar um trabalho em um contexto familiar - relacionando-o com coisas já conhecidas (RORTY, 1999, p. 133, tradução nossa ${ }^{5}$ ).

\footnotetext{
${ }^{4}$ When we read comics, we make a series of aesthetic and philosophical choices. Although these choices are usually made subconsciously, they're nevertheless real decisions that we face every time we open the comics section of the newspaper or crack open a new comic book. From the very outset, then, the form of comics - its language and how we understand it-is rife with philosophical quandaries. Once we start analyzing the contents of comics, we can face its theoretical concerns through its various storylines, narrative arcs, drawing styles, and commentary.

${ }^{5}$ You cannot, for example, find inspirational value in a text at the same time that you are viewing it as the product of a mechanism of cultural production. To view a work in this way gives understanding but not hope, knowledge but not self-transformation. For knowledge is a matter of putting a work in a familiar context - relating it to things already known.
} 
Sendo assim, o autor também aborda a importância da linguagem para a formação do ser humano moral. Ele explica que a linguagem, por meio da literatura, ajuda o ser humano a fazer mudanças positivas em relação ao outro. O outro, dentro do contexto da solidariedade, existe e não apenas o indivíduo que constrói seu próprio caráter

[...] substituir a demonstração pela dialética, como método da filosofia, ou descartar a teoria da verdade calcada na correspondência, não constitui uma descoberta sobre a natureza de uma entidade preexistente, chamada "filosofia" ou "verdade". Equivale a mudar nossa maneira de falar e, com isso, a mudar o que queremos fazer e o que pensamos ser (RORTY, 2007, p. 51-52).

Outros textos do filósofo neopragmatista também tratam de questões similares. Como Persuasion is a good thing, uma entrevista que ele deu em 1998 em Munique e que trata dos conceitos de contingência, ironia e solidariedade, além de citar a importância da literatura na filosofia e na vida em geral (RORTY, 2006). Já em "A trajetória do pragmatista", ele explica o porquê de ser antiessencialista, que as descrições são avaliadas, analisadas de acordo com a eficácia, não por sua fidelidade ao objeto descrito (RORTY, 1993b). E também em "Direitos humanos, racionalidade e sentimentalidade", no qual ele explica as questões morais de acordo com o racional e o sentimental (RORTY, 2005).

Partindo deste ponto de vista, escolhemos as webcomics Zen Pencils, dez tiras que abordam estas questões morais e éticas. As tiras de Zen Pencils, o foco principal da pesquisa, são, em grande parte, motivacionais. Zen Pencils conta histórias da vida de certas personalidades (Frida Kahlo, Vincent Van Gogh, Steve Jobs etc.) com uma mensagem positiva, dependendo do personagem. Foram escolhidas dez tiras dentre várias que o site publica que mais chamaram a atenção dos autores deste trabalho, com base na sua experiência de vida. Analisaremos estas dez tiras de acordo com o neopragmatismo de Rorty.

\section{3 - Neopragmatismo e Zen Pencils}

Para iniciar este estudo, devemos apresentá-lo e entendê-lo. Zen Pencils são webtiras criadas por Gavin Aung Than, nascido em Perth, na Austrália. Começou 
a lançar as tiras em 2012 através de um blog. Com o sucesso dessas tiras, elas foram publicadas em outros meios de comunicação como The Washington Post, The Huffington Post, Slate, Mashable, Upworthy, Buzzfeed, Gawker, The A.V. Club, Brain Pickings, Comic Book Resources, National Geographic, ProBlogger and The Design Files.

O site apresenta uma coleção de tiras de Than que foram traduzidas para várias línguas estrangeiras, incluindo português brasileiro. Os tradutores são pessoas de diferentes partes do mundo. Ele também divulga uma loja virtual dos produtos das tiras, os contatos do autor em redes sociais e pôsteres. As tiras são adaptações de frases motivacionais de pessoas famosas.

De acordo com o próprio autor, em seu site oficial,

\begin{abstract}
Eu perderia tempo lendo páginas da Wikipedia, principalmente biografias sobre pessoas cujas vidas eram muito mais interessantes que a minha. Suas histórias e citações acabaram me inspirando a deixar meu trabalho para me concentrar no que realmente queria fazer. A ideia de pegar essas citações inspiradoras, combinando-as com o meu amor por desenhar e compartilhá-las com outras pessoas, levou à criação dos Zen Pencils (THAN, 2012. Tradução nossa. ${ }^{6}$ ).
\end{abstract}

As dez tiras escolhidas são todas motivacionais e refletem no comportamento do autor de ter deixado seu trabalho prévio, criando uma abordagem da busca pela felicidade, mesmo que a pessoa tenha que passar por um período bastante difícil. Em si, as tiras mostram conexões da ética e moral na vida de um certo indivíduo - com o qual o leitor pode se identificar.

A primeira conta a história de Steve Jobs, intitulada "Seu tempo é curto" (Figura 1):

\footnotetext{
${ }^{6}$ I would waste time reading Wikipedia pages, mainly biographies about people whose lives were a lot more interesting than mine. Their stories and quotes eventually inspired me to leave my job to focus on what I really wanted to do. The idea of taking these inspiring quotes, combining them with my love of drawing and sharing them with others led to the creation of Zen Pencils. Disponível em: https://zenpencils.com/about/. Acesso em: 22 nov. 2019.
} 
Figura 1 - Steve Jobs (Seu tempo é curto)
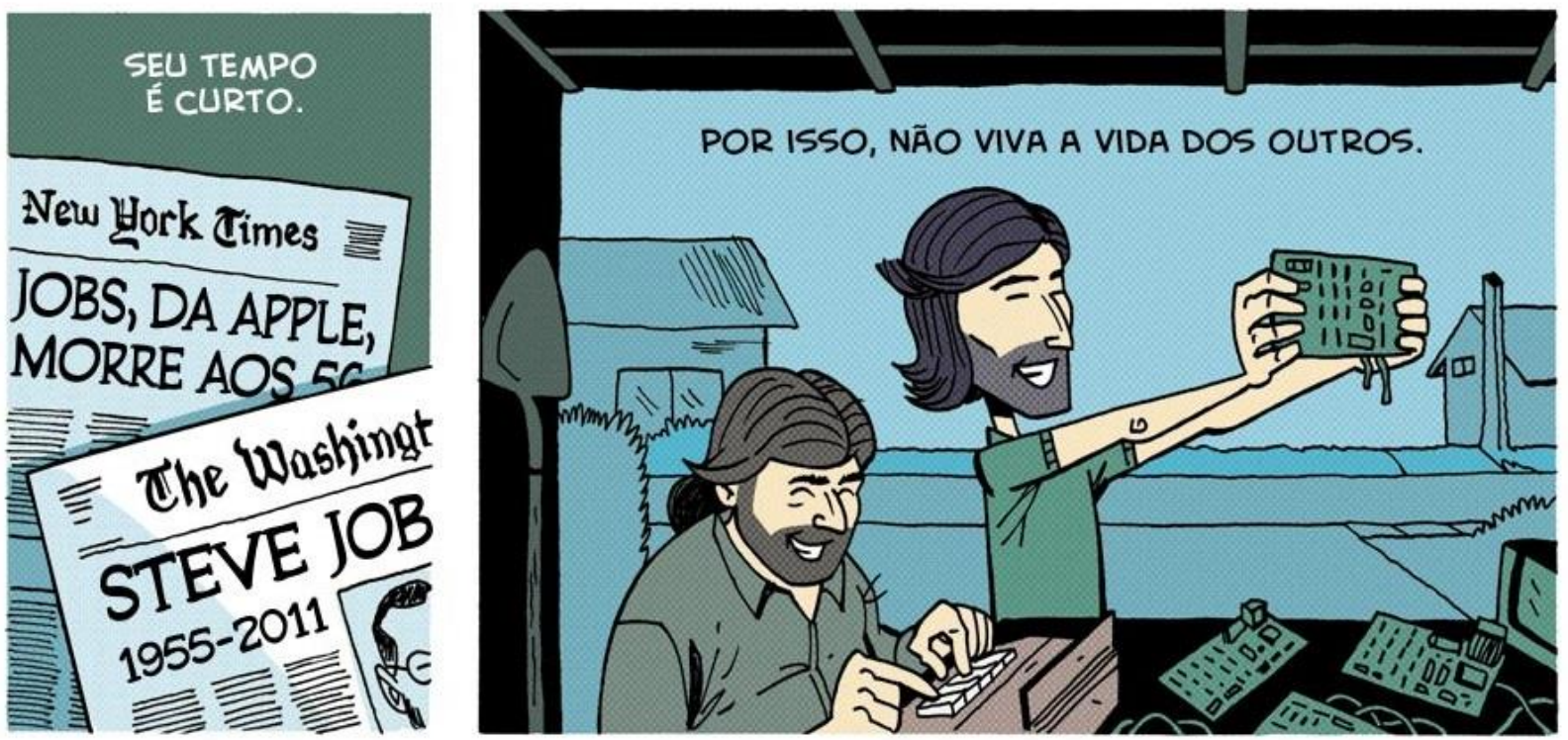

Fonte: https://www.zenpencils.com/comic/16-seu-tempo-e-curto/. Acesso em 14 nov. 2011.

De acordo com o próprio autor, essa tira é uma seção muito pequena retirada do discurso de Steve Jobs no início de trabalho de Stanford em 2005. Na tira, o quadrinista explica a importância de nós seguirmos nossos próprios sonhos, mesmo que muitas opiniões sejam diferentes, porque o tempo que temos é curto.

Observe que, na tira, o autor desenhou um quadrinho sobre as críticas das escolhas de Steve Jobs. Trabalhar em algo para ganhar dinheiro e se sustentar é algo comum na sociedade, e por isso, as pessoas, na tira, julgaram Steve Jobs por fazer algo diferente.

Rorty (2007, p. 166) defende que "[...] a tarefa de transformar sua situação em linguagem tem que ser executada para elas (vítimas) por outras pessoas. O romancista, o poeta ou o jornalista liberais são bons nisso". Ou seja, é fácil se identificar com uma tira em quadrinhos por uma linguagem que aborda estas questões.

Todos os seres humanos carregam um conjunto de palavras que empregam para justificar seus atos, suas crenças ou convicções e sua vida. [...] São palavras com que narramos, ora em caráter prospectivo, ora retrospectivamente, a história de nossa vida. Chamo a essas palavras o "vocabulário final" de uma pessoa (RORTY, 2007, p. 133). 
Tanto Steve Jobs quanto o autor da tira utilizam seus "vocabulários finais" a fim de demonstrarem suas dificuldades e vitórias para inspirarem outras pessoas a fazerem o mesmo. "Seu tempo é curto" é uma sentença que certamente resume toda a tira, que mostra os jornais relatando a morte de Steve Jobs.

Seguindo a mesma linha da tirinha de Steve Jobs, a de Lao Tzu (Figura 2) complementa com o método de "alimentar" seus sonhos.

Figura 2 - Lao Tzu (Alimentar os sonhos)

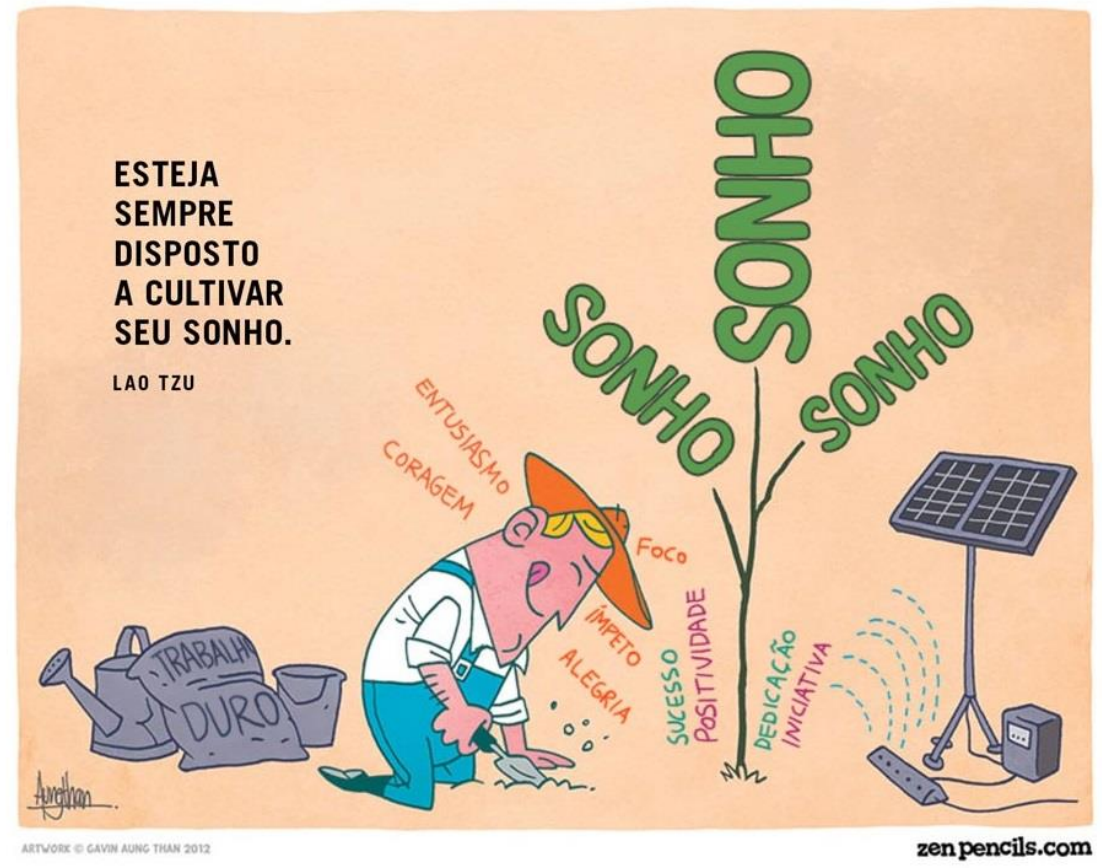

Fonte: https://www.zenpencils.com/comic/18-alimentar-os-sonhos/. Acesso em: 14 nov. 2021.

É interessante ressaltar que o autor utilizou de uma narrativa gráfica denotativa para explicar uma ideia. Ou seja, na frase de Lao Tzu, "plantar o sonho" está em sentido conotativo ou figurado, mas o quadrinista usou a figura de um jardineiro para ilustrar seu pensamento. $O$ sentido das palavras e sua conexão com as ilustrações transmitem a mensagem de mudança e progresso morais do autor e de Lao Tzu.

Nas palavras de Rorty (2006, p. 67, tradução nossa7) "[...] a literatura é mais importante para o progresso moral, porque contribui para a ampliação da imaginação moral. Isso nos torna mais sensíveis, aprofundando nossa

\footnotetext{
7 Literature is more important for moral progress, because it contributes to the widening of the moral imagination. It makes us more sensitive by deepening our understanding of the motivations of, and of the differences among, our fellow humans.
} 
compreensão das motivações e das diferenças entre nossos semelhantes". É justamente essa mensagem que o autor da tira está passando para seus leitores. Nós nos identificamos com ela, mesmo que sejamos indivíduos diferentes, e o conteúdo motivacional nos impulsiona a não desistirmos dos nossos sonhos.

A próxima tira (Figura 3) é sobre a vida de Bruce Lee, seguindo a mesma linha motivacional das várias histórias de Zen Pencils:

Figura 3 - Bruce Lee (Não existem limites)

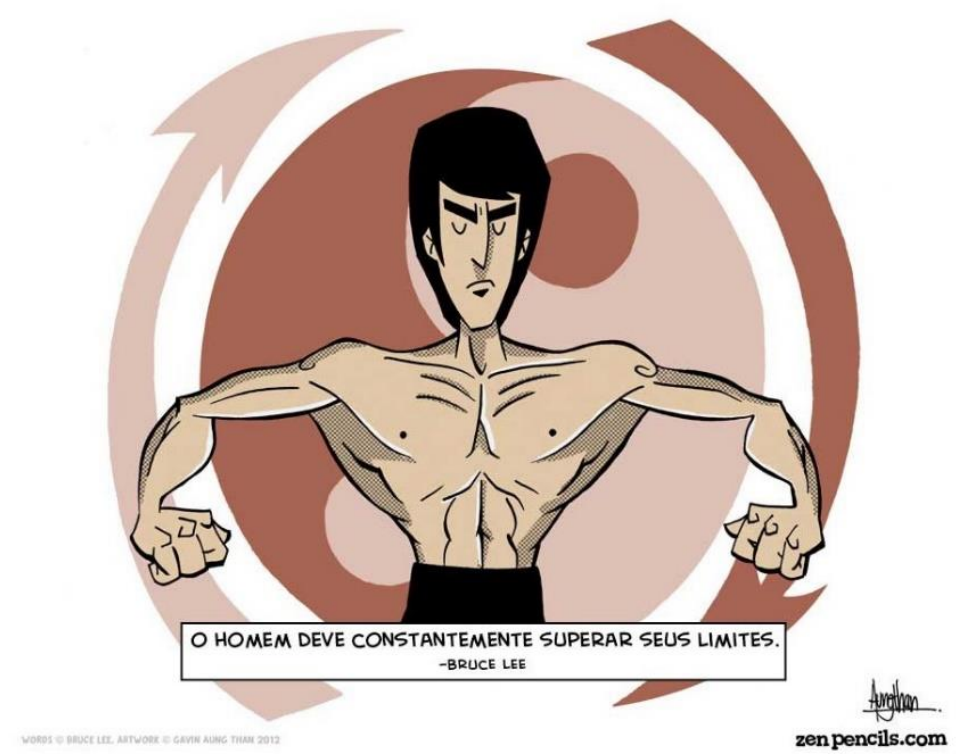

Fonte: https://www.zenpencils.com/comic/36-nao-existem-limites/. Acesso em: 14 nov. 2021.

Nesta tira, o autor demonstra o esforço de Bruce Lee para superar seus limites com cenas de lutas, muitos quadrinhos sem linguagem verbal. As dificuldades são o ponto principal desta história, na qual o autor, com a figura e uma frase de Bruce Lee, consegue, mais uma vez, mostrar a semelhança dele e de Bruce Lee com o leitor; cria-se empatia.

\begin{abstract}
A filosofia aspira à beleza, a arranjos agradáveis e harmoniosos de entidades já conhecidas. A literatura, em vez disso, se esforça em direção ao sublime. Quer dizer coisas nunca ditas antes. A tensão entre filosofia e literatura é a tensão entre o conhecido e o desconhecido (RORTY, 2006, p. 72, tradução nossa ${ }^{8}$ ).
\end{abstract}

\footnotetext{
${ }^{8}[\ldots]$ philosophy aspires to beauty, to agreeable and harmonious arrangements of already known entities. Literature, instead, strives toward the sublime. It wants to say things never said before. The tension between philosophy and literature is the tension between the known and the unknown. (RORTY, Richard. Persuasion is good thing.
} 
Ambas, a filosofia e a literatura, de acordo com Rorty (2006), devem andar juntas, explorando o conhecido e o desconhecido. O teor literário da tira é exposto ao conhecido por meio da filosofia por trás das palavras e das ilustrações. Nós, geralmente, não nos identificamos com o problema dos outros, mesmo que sejamos introduzidos nas questões da ética e moralidade. Por que é errado deixar um emprego para viver de algo que se gosta? Por que é errado focar em algo que a sociedade não considera apropriado? A literatura, neste caso, consegue quebrar essa barreira do indivíduo com a sociedade. É fácil julgar a vida de alguém quando você não faz ideia do que ele está sentindo, mas com a literatura, com o filme, com os quadrinhos, você tem um caminho a ser explorado e você acaba se identificando com ele.

A quarta tira (Figura 4) aborda a questão da preocupação:

Figura 4 - A preocupação (Por que me preocupar)

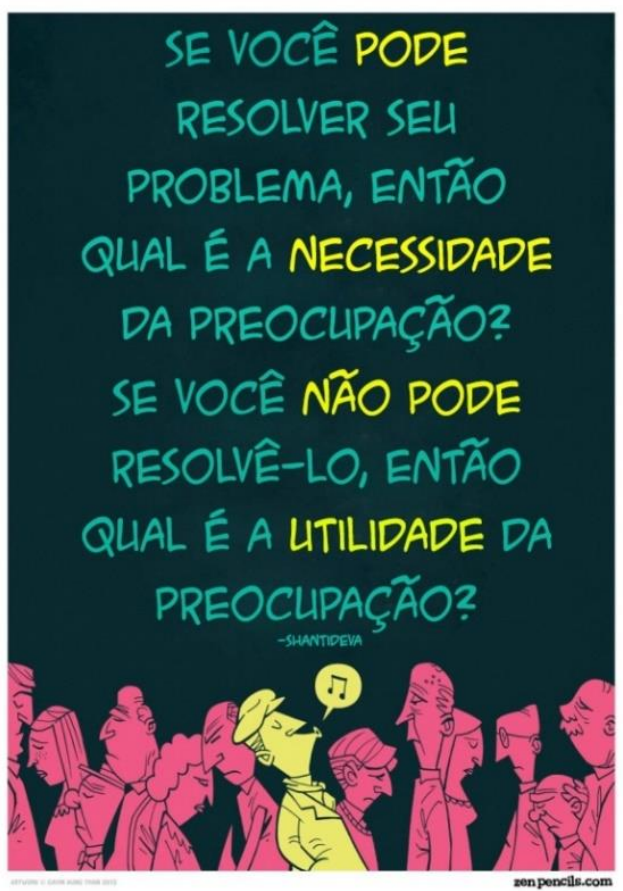

Fonte: https://www.zenpencils.com/comic/39-porque-me-preocupar/. Acesso em: 14 nov. 2021.

A ansiedade e preocupação tem sido um tema polêmico dentro da nossa sociedade. Pessoas cada vez mais tendem a esquecer seus próprios sonhos para conseguir sustento ou melhorar a condição de vida. Conectando esta história com as outras três explicadas, nós percebemos que o autor vê essas 
regras da sociedade com uma prisão em um mundo onde não há empatia com o próximo. Muitos podem julgar seu comportamento por não seguir uma linha "padrão", mas a felicidade é o que conta na vida deste autor. Por que se preocupar com algo que não vai resolver? E se sabe resolver, por que está preocupado? A ilustração da tira enfatiza essa ideia de que a preocupação causa tristeza.

Nessa perspectiva, Rorty (1993b, p. 111) explica que

[...] aqueles que desejam reduzir a objetividade à solidariedade - chamados "pragmatistas" - não requerem uma metafísica ou uma epistemologia. Eles veem a verdade como, na frase de William James, aquilo em que, para nós, é bom acreditar. Assim, eles não precisam de uma explicação de uma relação entre crenças e objetos chamada "correspondência", nem de uma explicação das habilidades cognitivas humanas que garanta que a nossa espécie é capaz de estabelecer aquela relação. (...) dizer que aquilo em que é racional acreditarmos agora pode não ser verdade é simplesmente dizer que alguém pode aparecer com uma ideia melhor.

O artista acredita em algo que a sociedade geralmente condena. De certa forma, somos obrigados a seguir certas regras, mas o pragmatismo abre suas portas para novos caminhos a fim de chegar ao respeito mútuo entre indivíduos e grupos culturais. Com sua tirinha, o autor conseguiu passar sua opinião e gerar uma certa empatia no leitor - quem nunca quis fazer algo que não o preocupasse? Mesmo que a sociedade não aceite, a tirinha fez seu papel de mostrar uma verdade do autor de forma clara, principalmente na ilustração.

A quinta tira (Figura 5), em que o autor fala do tema da verdade na figura e frase de Muhammad Ali, demonstra claramente esta questão do pragmatismo: 


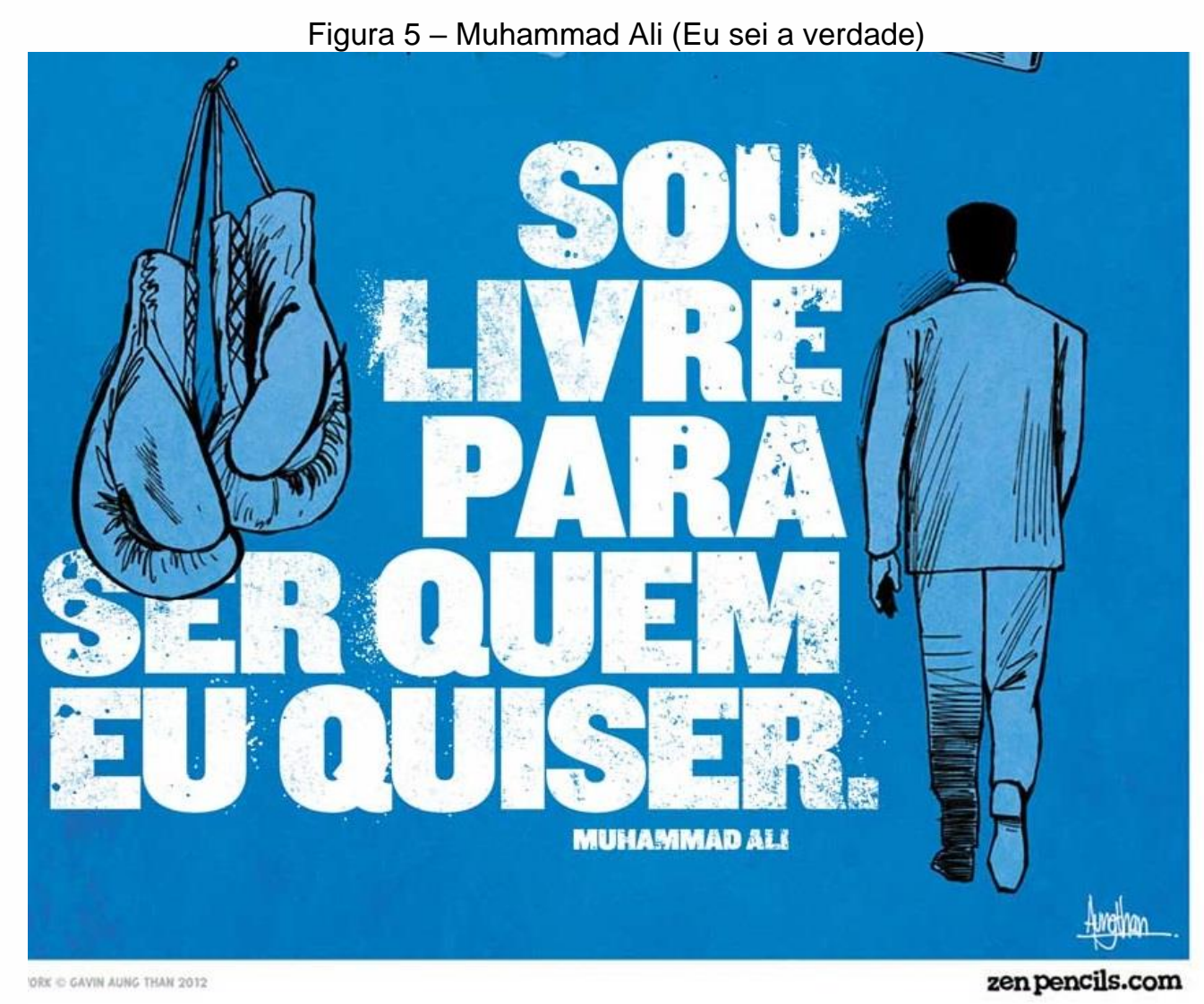

Fonte: https://www.zenpencils.com/comic/47-eu-sei-a-verdade/. Acesso em: 15 nov. 2021.

Para Rorty (1993b, p. 112), o pragmatista não possui uma teoria da verdade fixa. "Como um partidário da solidariedade, sua explicação do valor da investigação humana cooperativa tem apenas uma base ética, não uma base epistemológica ou metafísica." Ele busca a integração de todos os indivíduos no contexto social. Na tira, o autor conta uma breve história do que aconteceu com Muhammad Ali, mas que ele não se curvou à "verdade" de outros indivíduos. Para Ali, ele pode ser o que quiser, desde que ele alcance a felicidade. Esta é também a visão do autor, que demonstrou esse sentimento por meio de uma tira em quadrinhos. E, mais uma vez, o leitor se sensibiliza, mesmo não sendo mulçumano, mesmo não fazendo parte do grupo social de Ali. Esta é a solidariedade que Rorty defende, que pode ser achada na literatura, nos filmes e nos quadrinhos.

A próxima tira (Figura 6) é sobre uma frase de Kurt Vonnegut: 
Figura 6 - Kurt Vonnegut (A vida da Arte)
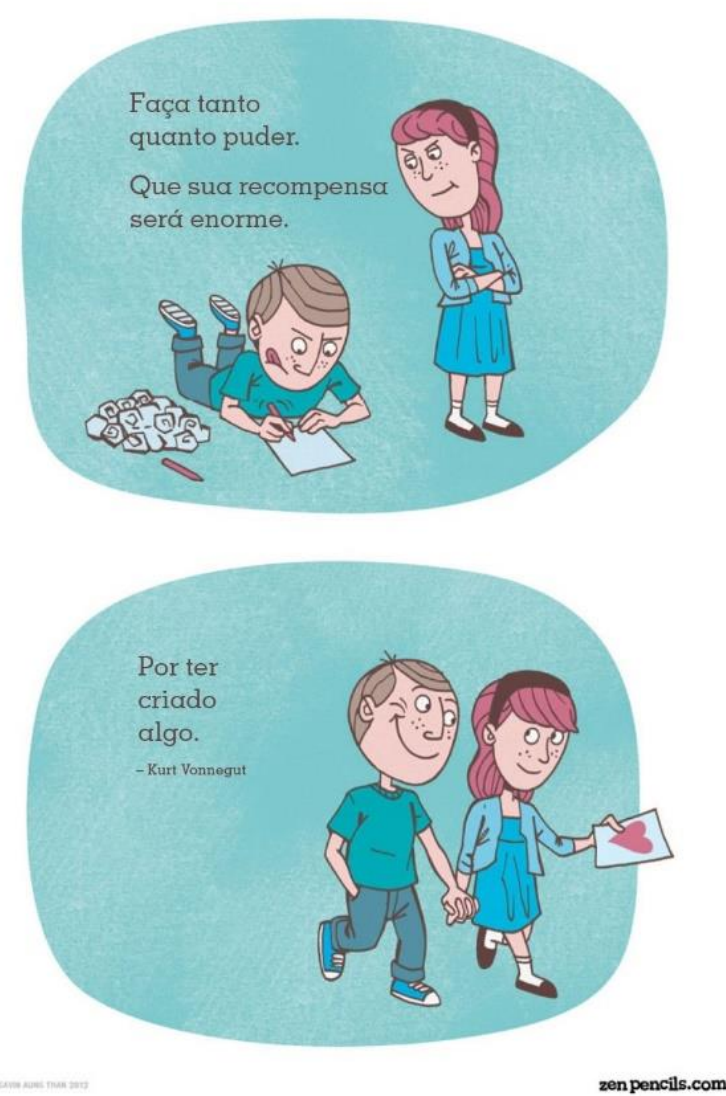

Fonte: https://www.zenpencils.com/comic/49-a-vida-da-arte/. Acesso em: 15 nov. 2021.

Essa tira demonstra a essência da vida do autor e das palavras de Rorty sobre a literatura e a arte. A arte ajuda as pessoas a entenderem o outro e a si mesmos. Rorty (2007, p. 20) diz que "esse processo de passar a ver outros seres humanos como 'um de nós', e não como 'eles', é uma questão de descrição detalhada de como são as pessoas desconhecidas e de redescrição de quem somos nós mesmos". Rorty defende que esta não é uma tarefa da teoria e sim "para gêneros como a etnografia, a reportagem jornalística, o livro de histórias em quadrinhos, o documento dramatizado e, em especial, o romance".

A Arte, de acordo com o autor e Vonnegut, ajuda o ser humano a suportar a vida. E para Rorty, ela abre portas para a empatia e o entendimento do outro.

Frida Kahlo é o próximo foco da tira a seguir (Figura 7). 
Figura 7 - Frida Kahlo (Estranho como eu)

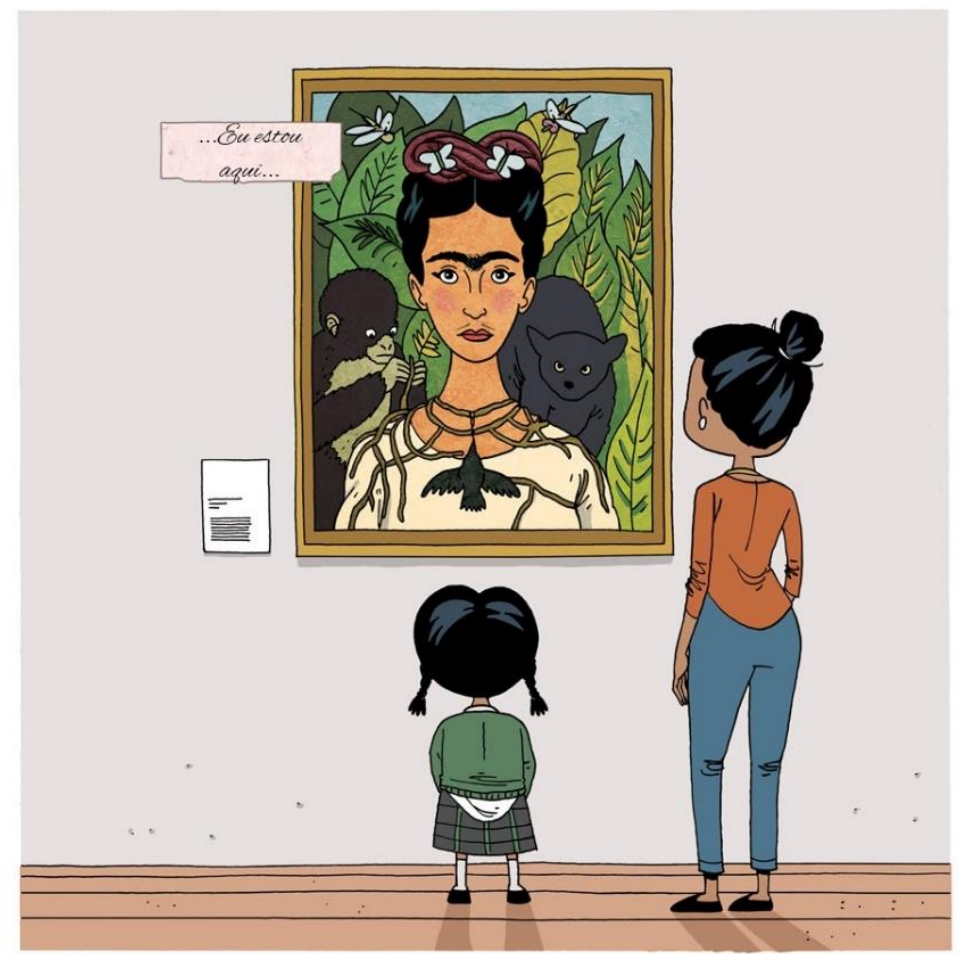

Fonte: https://www.zenpencils.com/comic/177-estranho-como-eul. Acesso em: 15 nov. 2021.

Esta tira narra a história de uma menina que, por ser diferente das outras, sofria preconceito e queria mudar para agradar a sociedade. Sua mãe mostrou a ela, por meio da arte e da artista Frida Kahlo, que ela ser diferente não significava que deveria seguir os padrões dos outros. Por mais que o leitor não tenha a mesma diferença da menina na história, ele se identificará com outro ponto em sua vida. É algo que as tiras de Zen Pencils trazem - solidariedade através da arte, verdades que buscam o bem estar do próximo, que ratificam a importância em aceitar todas as diferenças.

Dentro desta perspectiva, Rorty (2007, p. 20) enfatiza que

[...] a solidariedade humana seria vista não como um fato a ser reconhecido, mediante a eliminação do "preconceito" ou o mergulho em profundezas antes ocultas, mas como um objetivo a ser alcançado. $\mathrm{E}$ a ser alcançado não pela indagação, mas pela imaginação, pela capacidade imaginativa de ver pessoas estranhas como semelhantes sofredores.

É nessas condições que o neopragmatismo de Rorty explica como a filosofia deveria agir mediante o preconceito gerado pela sociedade. Essa sensibilidade é difícil de alcançar pelo pensamento, porque as pessoas são 
diferentes, mas a Arte em si consegue tocar neste ponto, um fator importante para nós alcançarmos a solidariedade.

A próxima tira (Figura 8) fala da curiosidade, de Albert Einstein.

Figura 8 - Albert Einstein (A coisa mais importante)

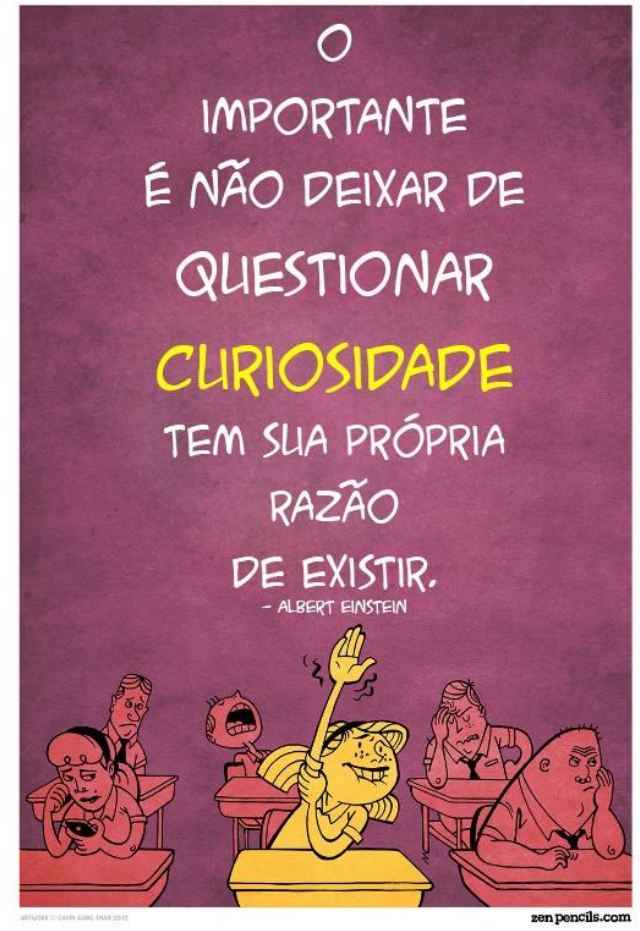

Fonte: https://www.zenpencils.com/comic/51-a-coisa-mais-importante/. Acesso em: 15 nov. 2021.

Questionar está relacionado à filosofia de muitos modos e o neopragmatismo de Rorty não acredita em uma verdade fixa como já mencionado neste artigo. $\mathrm{O}$ autor acredita que a curiosidade nos torna humanos. Sem ela, não teríamos uma razão de existir. Conhecer e questionar vários tópicos ajudam o indivíduo a achar sua própria verdade, desde que ela respeite o outro e que não anule o direto de alguém que difere da mesma.

A próxima tira remete a outra frase de Albert Einstein, que faz uma metáfora sobre a inteligência de cada indivíduo. Cada pessoa possui seu tipo de inteligência, de acordo com a tirinha - mas porque a sociedade não valoriza certos tipos de conhecimento, estes indivíduos acreditam ser "menos inteligentes" que os demais. É algo comum de vivenciar - o próprio autor da tirinha mostra sua vida pessoal e a de Einstein, e mesmo diferentes dos leitores, de novo, podemos perceber a solidariedade, a empatia que sentimos ao ler esta tirinha. 
Figura 9 - Albert Eistein (Todo indivíduo é um gênio)

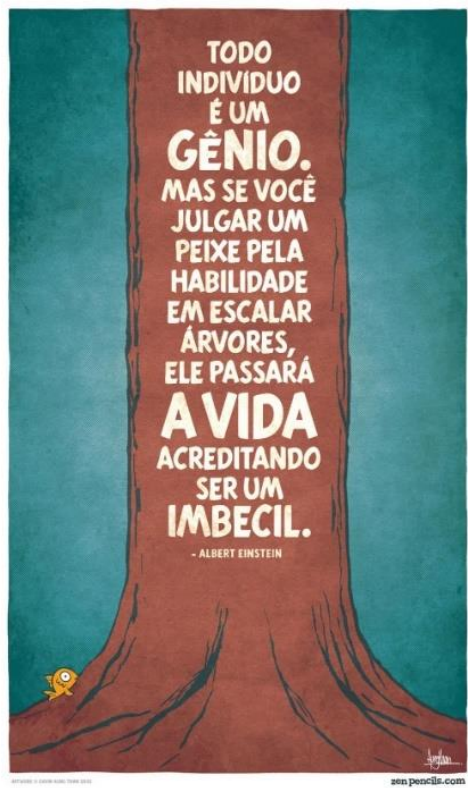

Fonte: https://www.zenpencils.com/comic/07-todo-individuo-e-um-genio/. Acesso em: 15 nov. 2021.

Rorty (2007, p. 314) afirma que "[...] nosso sentimento de solidariedade atinge sua intensidade máxima quando aqueles com quem nos solidarizamos são vistos como 'um de nós', expressão em que 'nós' significa algo menor e mais local do que a raça humana".

Por fim, temos uma tira (Figura 10) sobre uma reflexão de Ralph Waldo Emerson:

Figura 10 - Ralph Waldo Emerson (Faça-os chorar)
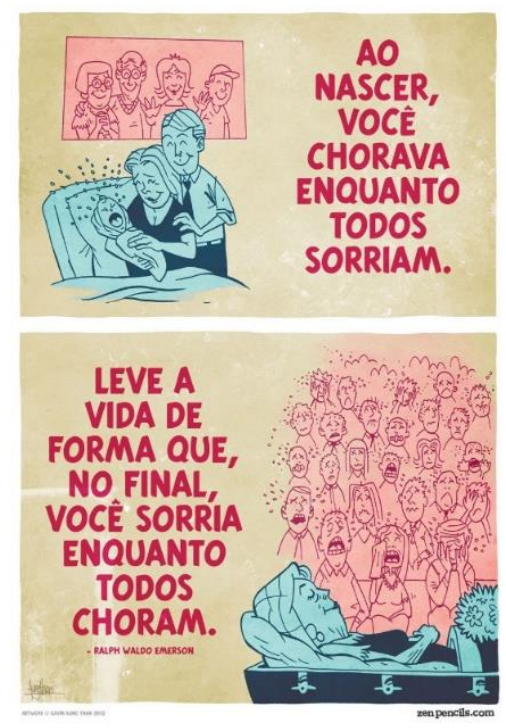

Fonte: https://www.zenpencils.com/comic/01-faca-os-chorar/. Acesso em: 15 nov. 2021. 
O foco principal desta tira, assim com todas as outras, é a felicidade. A motivação para viver bem, seguir seus próprios sonhos. A personagem da tira viveu bem, seguiu seus sonhos e morreu feliz. O que o autor e Emerson querem passar com esta mensagem é que a vida não é fácil, e por isso, o simbolismo da criança chorando ao nascer. Porém, se você levar sua vida do jeito que lhe faça sentir feliz, você morrerá em paz. Como na tira do Steve Jobs (Figura 1), a vida é curta, e, de acordo com o autor, devemos buscar nossa felicidade e não a dos outros. Senão, apenas existiremos, e não viveremos.

\section{Considerações finais}

O autor de Zen Pencils enfatiza em suas tiras a busca pela felicidade e sua própria verdade. Ele acredita que todos nós podemos vencer e ser felizes na vida. Ao mesmo tempo que ele incentiva o leitor à busca pela sua verdade, ele também adere à solidariedade que Rorty defende. O leitor sente uma empatia pelo diferente, mesmo que nunca tenha vivenciado o mesmo.

Conforme sugeriu Rorty (2007), os gêneros narrativos têm substituído paulatinamente o sermão e o tratado como elementos norteadores da mudança social e do progresso moral. Desse modo, tem-se percebido que a cultura pop em geral está contribuindo para formar o caráter moral das novas gerações. Portanto, é importante aprofundarmos os estudos dentro desta área do conhecimento, em especial no campo das história em quadrinhos, cujos temas principais ainda não são muito pesquisados nas universidades.

\section{Referências}

EISNER, Will. Narrativas gráficas. 3ª ed. São Paulo: Devir, 2013.

EISNER, Will. Quadrinhos e arte sequencial: princípios e práticas do lendário cartunista. 4. ed. São Paulo: Martins Fontes, 2010.

IANNONE, Leila Rentroia; IANNONE, Roberto Antonio. O mundo das histórias em quadrinhos. São Paulo: Moderna, 1996.

McCLOUD, Scott. Desenhando quadrinhos: os segredos das narrativas de quadrinhos, mangás e graphic novels. São Paulo: M. Books do Brasil Editora, 2008. 
McLAUGHLIN, Jeff. Comics as philosophy. Jackson: University of Mississipi Press, 2005.

MAGALHÃES, Henrique. A mutação radical dos fanzines. João Pessoa: Marca de Fantasia, 2005.

MORRIS, Tom; MORRIS, Matt. Los superhéroes y la filosofia. Barcelona: Blackie Books, 2010.

MOYA, Álvaro. História das histórias em quadrinhos. São Paulo: Brasiliense, 1993.

PESSOA, Alberto. A linguagem dos quadrinhos: definições, elementos e gêneros. João Pessoa: Marca de Fantasia, 2014.

RORTY, Richard. Contingência, ironia e solidariedade. São Paulo: Martins, 2007.

RORTY, Richard. Persuasion is a good thing. In: RORTY, Richard. Take care of freedom and truth will take care of itself: interviews with Richard Rorty. Stanford: Stanford University Press, 2006. p. 66-88.

RORTY, Richard. Solidariedade ou objetividade? Novos Estudos, CEBRAP. n. 36, p. 109-121, jul. 1993. (a)

RORTY, Richard. A trajetória do pragmatista. In: ECO, Umberto. Interpretação e superinterpretação. São Paulo: Martins Fontes, 1993. p.105-127. (b)

RORTY, Richard. Direitos humanos, racionalidade e sentimentalidade. In: RORTY, Richard. Verdade e progresso. Barueri: Manole, 2005. p. 199-223.

SANTOS, Roberto; CORRÊA, Victor; TOMÉ, Marcel. As webcomics brasileiras. In: LUIZ, Lúcio (Org.). Os quadrinhos na era digital. Nova Iguaçu: Marsupial Editora, 2013. p.3550 .

THAN, Gavin Aung. Zen Pencils. Cartoon Quotes from inspirational folks. 2012. Disponível em: https://zenpencils.com. Acesso em: 22 novembro 2019. 